$5^{\text {th }}$ International Conference on Research in

Behavioral and Social Science

Spain | Barcelona | December 7-9, 2018

\title{
Longitudinal Association Between Teacher-Child Relationship Quality and Children's Academic Association
}

\author{
Assistant Prof Dr. Najia Zulfiqar \\ Department of Psychology, The University of Haripur, KPK Pakistan.
}

The purpose of this study was to examine the longitudinal association between teacher-child relationship quality and children's academic competence along with studying three covariates of sex, race, and SES. Relationship quality, using STRS-SF, was examined in terms of teachers' perceptions of relational closeness and conflict with individual children in grades 3-5. Academic competence was examined using proxy measures of Woodcock-Johnson Psycho-educational Battery-Revised (WJ-R) and Academic Rating Scale. NICHD SECCYD Phase III (1999-2001) data were used for the present study that was collected from children $(n=1364)$ and teachers at participants' homes, schools, and in lab settings. Data were checked for statistical assumptions of missingness and normality prior to test of structural equation modeling. As expected, teacherchild relationship quality during early grades predicted relationship quality during later grades. Bivariate correlations indicated that relationship closeness and conflict were negatively correlated, and a high level of closeness and a low level of conflict with teachers predicted high academic competence among children. In addition, female, White, and high SES children had better academic competence, and experienced more closeness and less conflict with teachers than their counterparts. The fit indices for the baseline and modified models are discussed and recommendations are presented for future research to study relationship quality over transition to the middle school and to examine children's perception of relationship quality with teachers and parents.

Keywords: closeness, conflict, academic success, structural equation modeling, analysis of covariates 